\title{
Fluid Potential Fractal Dimension for Characterizing Shajara Reservoirs of the Permo-Carboniferous Shajara Formation, Saudi Arabia
}

\author{
Prof. Khalid Elyas Mohamed Elameen Alkhidir \\ Ph.D. Department of Petroleum and Natural Gas Engineering, College of Engineering, King Saud University, \\ Saudi Arabia \\ *Corresponding Author: Khalid Elyas Mohamed Elameen Alkhidir, Ph.D. Department of Petroleum \\ and Natural Gas Engineering, College of Engineering, King Saud University, Saudi Arabia
}

\begin{abstract}
The quality and assessment of a reservoir can be documented in details by the application of fluid potential. This research aims to calculate fractal dimension from the relationship among fluid potential, maximum fluid potential and wetting phase saturation and to approve it by the fractal dimension derived from the relationship among capillary pressure and wetting phase saturation. Two equations for calculating the fractal dimensions have been employed. The first one describes the functional relationship between wetting phase saturation, fluid potential, and maximum fluid potential and fractal dimension. The second equation implies to the wetting phase saturation as a function of capillary pressure and the fractal dimension. Two procedures for obtaining the fractal dimension have been utilized. The first procedure was done by plotting the logarithm of the ratio between fluid potential and maximum fluid potential versus logarithm wetting phase saturation. The slope of the first procedure $=3-D f$ (fractal dimension). The second procedure for obtaining the fractal dimension was determined by plotting the logarithm of capillary pressure versus the logarithm of wetting phase saturation. The slope of the second procedure $=D f-3$. On the basis of the obtained results of the fabricated stratigraphic column and the attained values of the fractal dimension, the sandstones of the Shajara reservoirs of the Shajara Formation were divided here into three units.
\end{abstract}

Keywords: Shajara Reservoirs, Shajara Formation, fluid potential fractal dimension, Capillary pressure fractal dimension

\section{INTRODUCTION}

Seismo electric effects related to electro kinetic potential, dielectric permittivity, pressure gradient, fluid viscosity, and electric conductivity was first reported by [1]. Capillary pressure follows the scaling law at low wetting phase saturation was reported by [2]. Seismo electric phenomenon by considering electro kinetic coupling coefficient as a function of effective charge density, permeability, fluid viscosity and electric conductivity was reported by [3]. The magnitude of seismo electric current depends porosity, pore size, zeta potential of the pore surfaces, and elastic properties of the matrix was investigated by [4]. The tangent of the ratio of converted electric field to pressure is approximately in inverse proportion to permeability was studied by [5]. Permeability inversion from seismoelectric log at low frequency was studied by [6]. They reported that, the tangent of the ratio among electric excitation intensity and pressure field is a function of porosity, fluid viscosity, frequency, tortuosity, fluid density and Dracy permeability. A decrease of seismo electric frequencies with increasing water content was reported by [7]. An increase of seismo electric transfer function with increasing water saturation was studied by [8]. An increase of dynamic seismo electric transfer function with decreasing fluid conductivity was described by [9]. The amplitude of seismo electric signal increases with increasing permeability which means that the seismo electric effects are directly related to the permeability and can be used to study the permeability of the reservoir was illustrated by [10]. Seismo electric coupling is frequency dependent and decreases expontialy when frequency increases was demonstrated by [11]. An increase of permeability with increasing pressure head and bubble pressure fractal dimension was reported by $[12,13]$. An increase of geometric and arithmetic relaxtion time of induced polarization fractal dimension with permeability increasing and grain size 
was described by $[14,15,16]$. An increase of seismo electric field fractal dimension with increasing permeability and grain size was described by [17]. An increase of resistivity fractal dimension with increasing permeability and grain size was illustrated by [18]. An increase of electro kinetic fractal dimension with increasing permeability and grain size was demonstrated by[19]. An increase of electric potential energy with increasing permeability and grain size was defined by [20]. An increase of electric potential gradient fractal dimension with increasing permeability and grain size was defined by [21]. An increase of differential capacity fractal dimension with increasing permeability and grain size was described by [22].

\section{MATERial AND Method}

Sandstone samples were collected from the surface type section of the Permo-Carboniferous Shajara Formation, latitude $26^{\circ} 52^{\prime} 17.4^{\prime \prime}$, longitude $43^{\circ} 36^{\prime} 18^{\prime \prime}$. (Figure1). Porosity was measured on collected samples using mercury intrusion Porosimetry and permeability was derived from capillary pressure data. The purpose of this paper is to obtain fluid potential fractal dimension and to confirm it by capillary pressure fractal dimension. The fractal dimension of the first procedure is determined from the positive slope of the plot of logarithm of the ratio of fluid potential to maximum fluid potential $\log \left(\mathrm{FP}^{1 / 2} / \mathrm{FP}^{1 / 2}{ }_{\max }\right)$ versus $\log$ wetting phase saturation $(\operatorname{logSw})$. Whereas the fractal dimension of the second procedure is determined from the negative slope of the plot of logarithm of $\log$ capillary pressure $(\log \mathrm{Pc})$ versus logarithm of wetting phase saturation $(\log \mathrm{Sw})$.

The fluid potential can be scaled as

$\mathrm{Sw}=\left[\frac{\mathrm{FP}^{\frac{1}{2}}}{\mathrm{FP}_{\max }^{\frac{1}{2}}}\right]^{[3-\mathrm{Df}]}$

Where $\mathrm{Sw}$ the water saturation, $\mathrm{FP}$ the fluid potential in square meter / square second, $\mathrm{FP}_{\max }$ the maximum fluid potential in square meter / square second, and Df the fractal dimension.

Equation 1 can be proofed from

$\mathrm{q}=\mathrm{PD} * \mathrm{~A}$

Where $\mathrm{q}$ the electric charge in coulomb, PD the polarization density in coulomb / square meter, and A the area in square meter.

The area can be scaled as

$\mathrm{A}=\mathrm{FP} * \mathrm{~T}^{2}$

Where A the area in square meter, FP the fluid potential in square meter / square second, $\mathrm{T}$ the time in second.

Insert equation 3 into equation 2

$\mathrm{q}=\mathrm{PD} * \mathrm{FP} * \mathrm{~T}^{2}$

The electric charge q can be scaled as

$\mathrm{q}=\mathrm{i} * \mathrm{~T}$

Where $\mathrm{q}$ the electric charge in coulomb, $\mathrm{i}$ the electric current in ampere, and $\mathrm{T}$ the time in second.

Insert equation 5 into equation 4

$\mathrm{i} * \mathrm{~T}=\mathrm{PD} * \mathrm{FP} * \mathrm{~T}^{2}$

The electric current $\mathrm{i}$ can be scaled as

$\mathrm{i}=\mathrm{A} * \mathrm{~J}$

Where $i$ the electric current in ampere, A the area in square meter, and $\mathrm{J}$ the electric current density in ampere /square meter.

Insert equation 7 into equation 6

$\mathrm{A} * \mathrm{~J} * \mathrm{~T}=\mathrm{PD} * \mathrm{FP} * \mathrm{~T}^{2}$

The area $\mathrm{A}$ can be scaled as

$\mathrm{A}=4 * 3.14 * \mathrm{r}^{2}$

Where $\mathrm{A}$ the area in square meter, and $\mathrm{r}$ the pore radius in meter 
Insert equation 9 into equation 8

$$
4 * 3.14 * \mathrm{r}^{2} * \mathrm{~J} * \mathrm{~T}=\mathrm{PD} * \mathrm{FP} * \mathrm{~T}^{2}
$$

The maximum pore radius $\mathrm{r}_{\max }$ can be scaled as

$$
4 * 3.14 * \mathrm{r}_{\max }^{2} * \mathrm{~J} * \mathrm{~T}=\mathrm{PD} * \mathrm{FP}_{\max } * \mathrm{~T}^{2}
$$

Divide equation 10 by equation 11

$$
\left[\frac{4 * 3.14 * \mathrm{r}^{2} * \mathrm{~J} * \mathrm{~T}}{4 * 3.14 * \mathrm{r}_{\max }^{2} * \mathrm{~J} * \mathrm{~T}}\right]=\left[\frac{\mathrm{PD} * \mathrm{FP} * \mathrm{~T}^{2}}{\mathrm{PD} * \mathrm{FP}_{\max } * \mathrm{~T}^{2}}\right]
$$

Equation 12 after simplification will become

$$
\left[\frac{\mathrm{r}^{2}}{\mathrm{r}_{\max }^{2}}\right]=\left[\frac{\mathrm{FP}}{\mathrm{FP}_{\max }}\right]
$$

Take the square root of equation 13

$$
\sqrt{\left[\frac{\mathrm{r}^{2}}{\mathrm{r}_{\max }^{2}}\right]}=\sqrt{\left[\frac{\mathrm{FP}}{\mathrm{FP}_{\max }}\right]}
$$

Equation 14 after simplification will become

$$
\left[\frac{\mathrm{r}}{\mathrm{r}_{\text {max }}}\right]=\left[\frac{\mathrm{FP}^{\frac{1}{2}}}{\mathrm{FP}_{\text {max }}^{\frac{1}{2}}}\right]
$$

Take the logarithm of equation 15

$$
\begin{aligned}
& \log \left[\frac{\mathrm{r}}{\mathrm{r}_{\text {max }}}\right]=\log \left[\frac{\mathrm{FP}^{\frac{1}{2}}}{\mathrm{FP}_{\text {max }}^{\frac{1}{2}}}\right] \\
& \text { But; } \log \left[\frac{\mathrm{r}}{\mathrm{r}_{\max }}\right]=\left[\frac{\log \mathrm{Sw}}{3-\mathrm{Df}}\right]
\end{aligned}
$$

Insert equation 17 into equation 16

$$
\left[\frac{\log \mathrm{Sw}}{3-\mathrm{Df}}\right]=\log \left[\frac{\mathrm{FP}^{\frac{1}{2}}}{\mathrm{FP}_{\mathrm{max}}^{\frac{1}{2}}}\right]
$$

Equation 18 after log removal will become

$\mathrm{Sw}=\left[\frac{\mathrm{FP}^{\frac{1}{2}}}{\mathrm{FP}_{\max }^{\frac{1}{2}}}\right]^{[3-\mathrm{Df}]}$

Equation 19 the proof of equation 1 which relates the water saturation, fluid potential, the maximum fluid potential, and the fractal dimension.

The capillary pressure can be scaled as

$$
\mathrm{Sw}=[\mathrm{Df}-3] * \mathrm{Pc} * \text { constant }
$$

Where $\mathrm{Sw}$ the water saturation, Pc the capillary pressure and Df the fractal dimension.

\section{RESULTS AND DISCUSSION}

Based on field observation the Shajara Reservoirs of the Permo-Carboniferous Shajara Formation were divided here into three units as described in Figure1.These units from bottom to top are: Lower Shajara Reservoir, Middle Shajara reservoir, and Upper Shajara Reservoir. Their attained results of the fluid potential fractal dimension and capillary pressure fractal dimension are exhibited in Table 1. Based on the achieved results it was found that the fluid potentialfractal dimension is equal to the capillary pressure fractal dimension. The maximum value of the fractal dimension was found to be 
Fluid Potential Fractal Dimension for Characterizing Shajara Reservoirs of the Permo-Carboniferous Shajara Formation, Saudi Arabia

2.7872 allocated to sample SJ13 from the Upper Shajara Reservoir as verified in Table 1. Whereas the minimum value of the fractal dimension 2.4379 was reported from sample SJ3 from the Lower Shajara reservoir as shown in Table1. The fluid potential fractal dimension and capillary pressure fractal dimension were detected to increase with increasing permeability as proofed in Table1 owing to the possibility of having interconnected channels.

Table1. Petrophysical model showing the three Shajara Reservoir Units with their corresponding values of fluid potential fractal dimension and capillary pressure fractal dimension

\begin{tabular}{|c|c|c|c|c|c|c|c|c|}
\hline Formation & Reservoir & Sample & $\begin{array}{c}\text { Porosity } \\
\%\end{array}$ & $\begin{array}{c}\mathrm{k} \\
(\mathrm{md})\end{array}$ & $\begin{array}{c}\text { Positive } \\
\text { slope of the } \\
\text { first } \\
\text { procedure } \\
\text { Slope=3-Df }\end{array}$ & $\begin{array}{l}\text { Negative } \\
\text { slope of the } \\
\text { second } \\
\text { procedure } \\
\text { Slope=Df-3 }\end{array}$ & $\begin{array}{c}\text { Fluid } \\
\text { potential } \\
\text { fractal } \\
\text { dimension }\end{array}$ & $\begin{array}{c}\text { Capillary } \\
\text { pressure } \\
\text { fractal } \\
\text { dimension }\end{array}$ \\
\hline \multirow{10}{*}{ 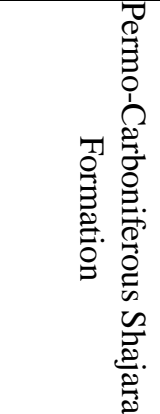 } & \multirow{3}{*}{$\begin{array}{c}\text { Upper } \\
\text { Shajara } \\
\text { Reservoir }\end{array}$} & SJ13 & 25 & 973 & 0.2128 & -0.2128 & 2.7872 & 2.7872 \\
\hline & & SJ12 & 28 & 1440 & 0.2141 & -0.2141 & 2.7859 & 2.7859 \\
\hline & & SJ11 & 36 & 1197 & 0.2414 & -0.2414 & 2.7586 & 2.7586 \\
\hline & \multirow{3}{*}{$\begin{array}{c}\text { Middle } \\
\text { Shajara } \\
\text { Reservoir }\end{array}$} & SJ9 & 31 & 1394 & 0.2214 & -0.2214 & 2.7786 & 2.7786 \\
\hline & & SJ8 & 32 & 1344 & 0.2248 & -0.2248 & 2.7752 & 2.7752 \\
\hline & & SJ7 & 35 & 1472 & 0.2317 & -0.2317 & 2.7683 & 2.7683 \\
\hline & \multirow{4}{*}{$\begin{array}{c}\text { Lower } \\
\text { Shajara } \\
\text { Reservoir }\end{array}$} & SJ4 & 30 & 176 & 0.3157 & -0.3157 & 2.6843 & 2.6843 \\
\hline & & $\mathrm{SJ} 3$ & 34 & 56 & 0.5621 & -0.5621 & 2.4379 & 2.4379 \\
\hline & & SJ2 & 35 & 1955 & 0.2252 & -0.2252 & 2.7748 & 2.7748 \\
\hline & & SJ1 & 29 & 1680 & 0.2141 & -0.2141 & 2.7859 & 2.7859 \\
\hline
\end{tabular}

The Lower Shajara reservoir was symbolized by six sandstone samples (Figure 1), four of which label as SJ1, SJ2, SJ3 and SJ4 were carefully chosen for capillary pressure measurement as proven in Table1. Their positive slopes of the first procedure log of the fluid potential (FP) to maximum fluid potential $\left(\mathrm{FP}_{\max }\right)$ versus log wetting phase saturation $(\mathrm{Sw})$ and negative slopes of the second procedure $\log$ capillary pressure $(\mathrm{Pc})$ versus log wetting phase saturation $(\mathrm{Sw})$ are clarified in Figure 2, Figure 3, Figure 4, Figure 5 and Table 1. Their fluid potential fractal dimension and capillary pressure fractal dimension values are revealed in Table 1. As we proceed from sample SJ2 to SJ3 a pronounced reduction in permeability due to compaction was described from $1955 \mathrm{md}$ to $56 \mathrm{md}$ which reflects decrease in fluid potential fractal dimension from 2.7748 to 2.4379 as quantified in table 1. Again, an increase in grain size and permeability was proved from sample SJ4 whose fluid potential fractal dimension and capillary pressure fractal dimension was found to be 2.6843 as pronounced in Table 1 .

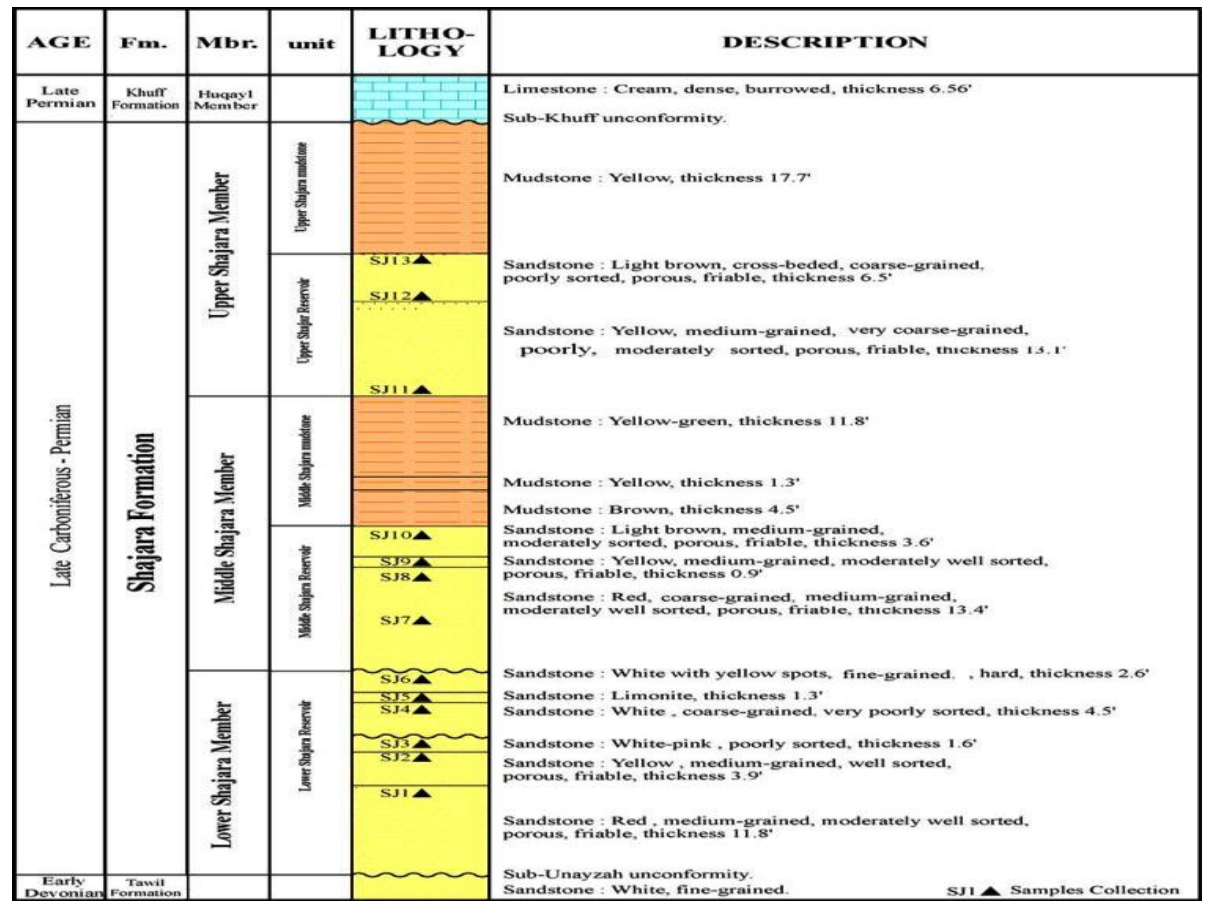

Figure1. Surface type section of the Shajara Reservoirs of the Permo-Carboniferous Shajara Formation, latitude $26^{\circ} 52^{\prime} 17.4^{\prime \prime}$, longitude $43^{\circ} 36^{\prime} 18^{\prime \prime}$. 
Fluid Potential Fractal Dimension for Characterizing Shajara Reservoirs of the Permo-Carboniferous Shajara Formation, Saudi Arabia

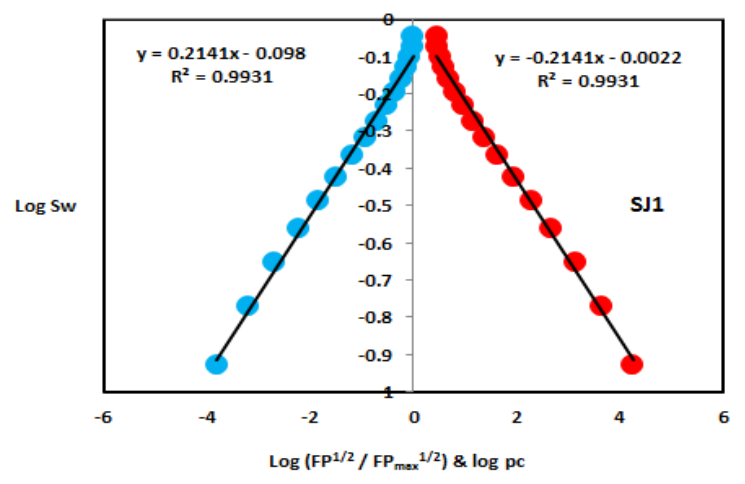

Figure2. $\log \left(F P^{1 / 2} / F P^{I / 2}{ }_{\max }\right) \& \log$ Pc versus log Sw of sample SJ1.

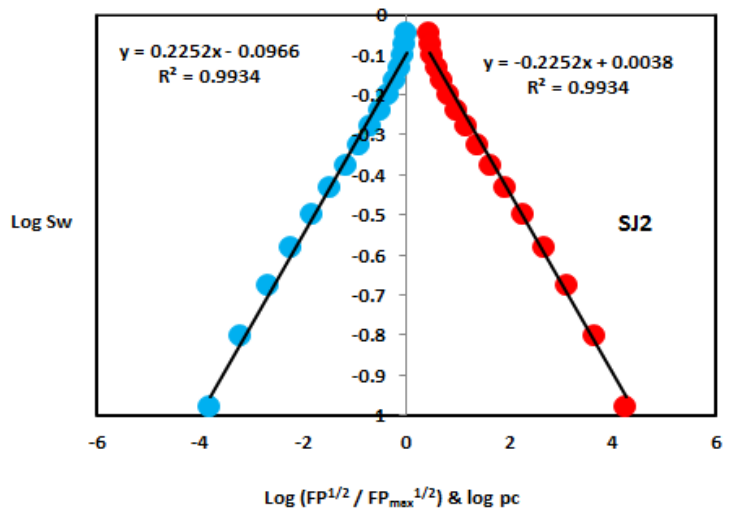

Figure3. Log (FP1/2/FP1/2max) \& log Pc versus log Sw of sample SJ2.

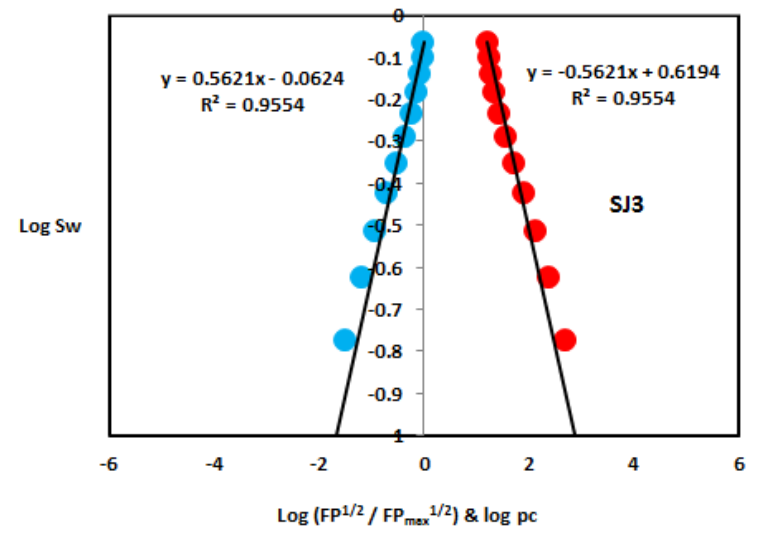

Figure4. $\log \left(F P^{1 / 2} / F P_{\text {max }}^{1 / 2}\right) \& \log$ Pc versus log Sw of sample SJ3.

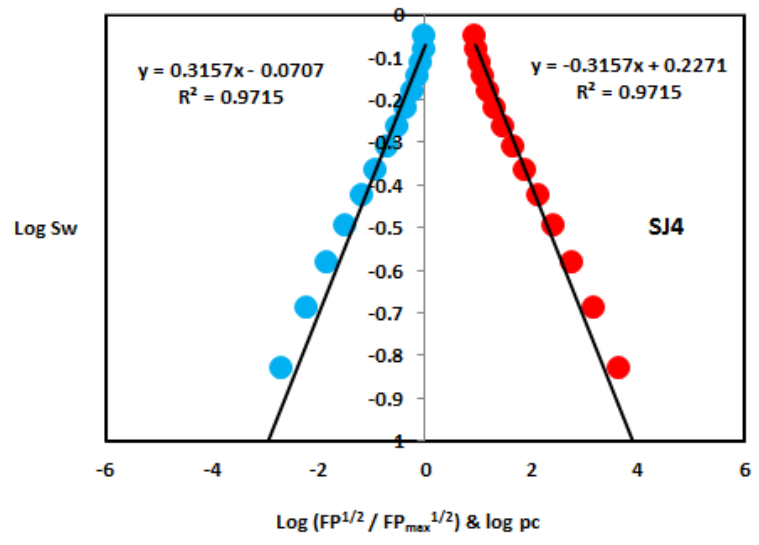

Figure5. $\log \left(F P^{I / 2} / F P_{\text {max }}^{l / 2}\right) \& \log$ Pc versus log Sw of sample SJ4. 
Fluid Potential Fractal Dimension for Characterizing Shajara Reservoirs of the Permo-Carboniferous Shajara Formation, Saudi Arabia

In contrast, the Middle Shajara reservoir which is separated from the Lower Shajara reservoir by an unconformity surface as revealed in Figure 1. It was nominated by four samples (Figure 1), three of which named as SJ7, SJ8, and SJ9 as illuminated in Table1 were chosen for capillary measurements as described in Table 1 . Their positive slopes of the first procedure and negative slopes of the second procedure are shown in Figure 6, Figure 7 and Figure 8 and Table 1. Furthermore, their fluid potential fractal dimensions and capillary pressure fractal dimensions show similarities as defined in Table 1.Their fractal dimensions are higher than those of samples SJ3 and SJ4 from the Lower Shajara Reservoir due to an increase in their permeability as explained in table 1.

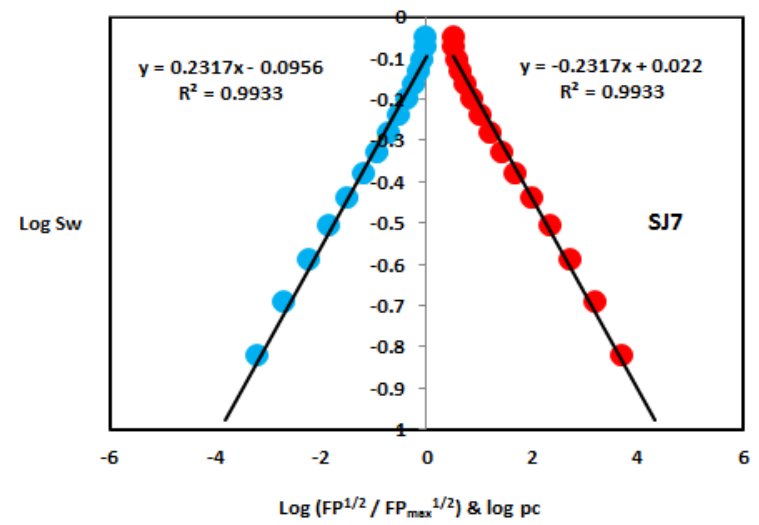

Figure6. $\log \left(F P^{1 / 2} / F P_{\text {max }}^{I / 2}\right) \& \log$ Pc versus log Sw of sample SJ7.

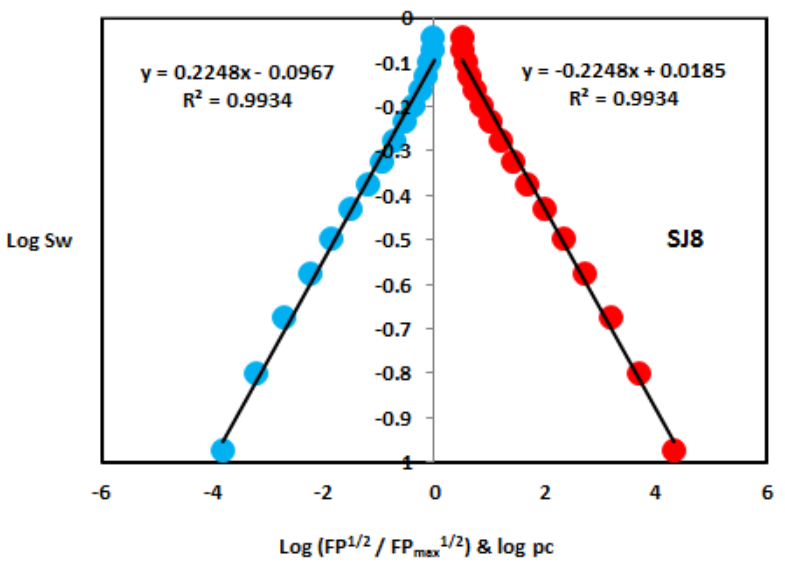

Figure7. $\log \left(F P^{1 / 2} / F P^{I / 2}{ }_{\max }\right) \& \log$ Pc versus log Sw of sample SJ8.

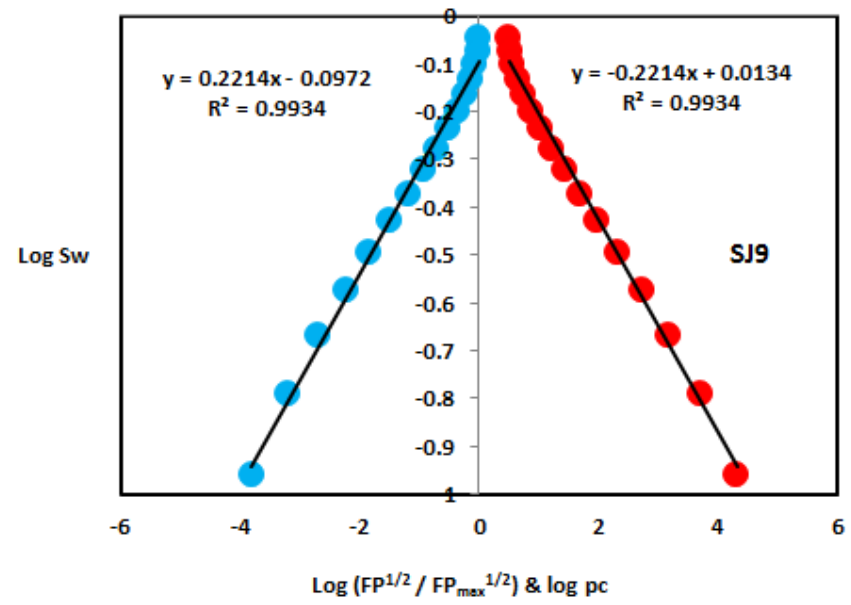

Figure8. $\log \left(F P^{1 / 2} / F P^{I / 2}{ }_{\max }\right) \& \log$ Pc versus log Sw of sample SJ9.

On the other hand, the Upper Shajara reservoir was separated from the Middle Shajara reservoir by yellow green mudstone as shown in Figure 1. It is defined by three samples so called SJ11, SJ12, SJ13 
Fluid Potential Fractal Dimension for Characterizing Shajara Reservoirs of the Permo-Carboniferous Shajara Formation, Saudi Arabia

as explained in Table 1. Their positive slopes of the first procedure and negative slopes of the second procedure are displayed in Figure 9, Figure 10 and Figure 11 and Table 1. Moreover, their fluid potential fractal dimension and capillary pressure fractal dimension are also higher than those of sample SJ3 and SJ4 from the Lower Shajara Reservoir due to an increase in their permeability as simplified in table 1.

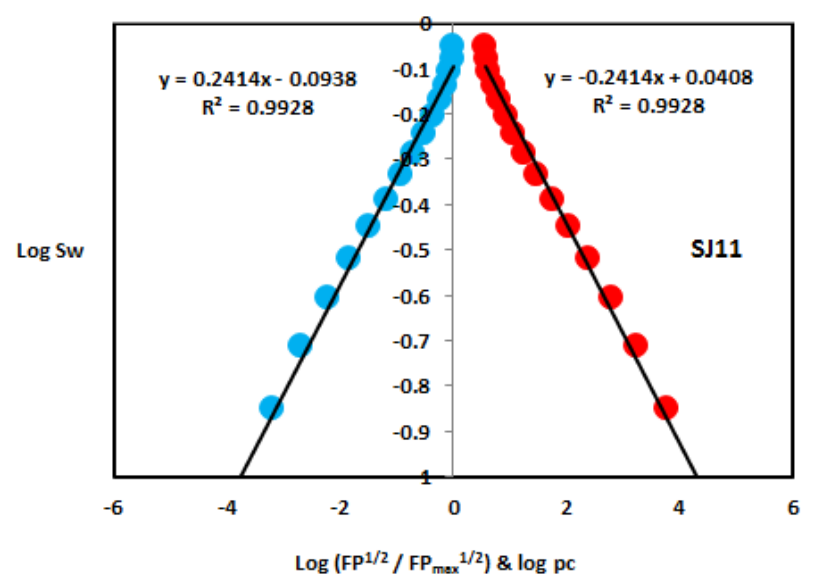

Figure9. $\log \left(F P_{1 / 2} / F P_{\text {max }}^{1 / 2}\right) \& \log$ Pc versus log Sw of sample SJ11.

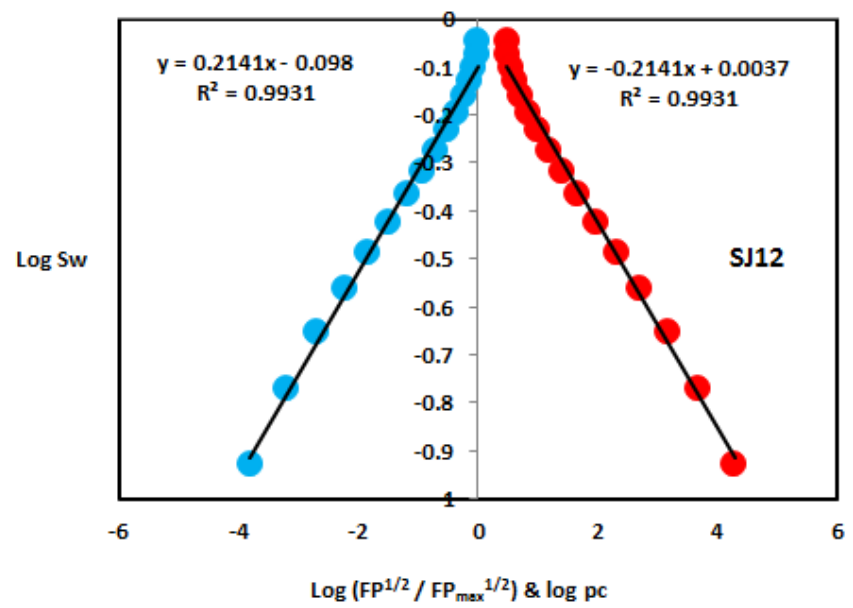

Figure10. $\log \left(F P_{1 / 2} / F P^{1 / 2}\right.$ max $) \& \log$ Pc versus $\log$ Sw of sample SJ12.

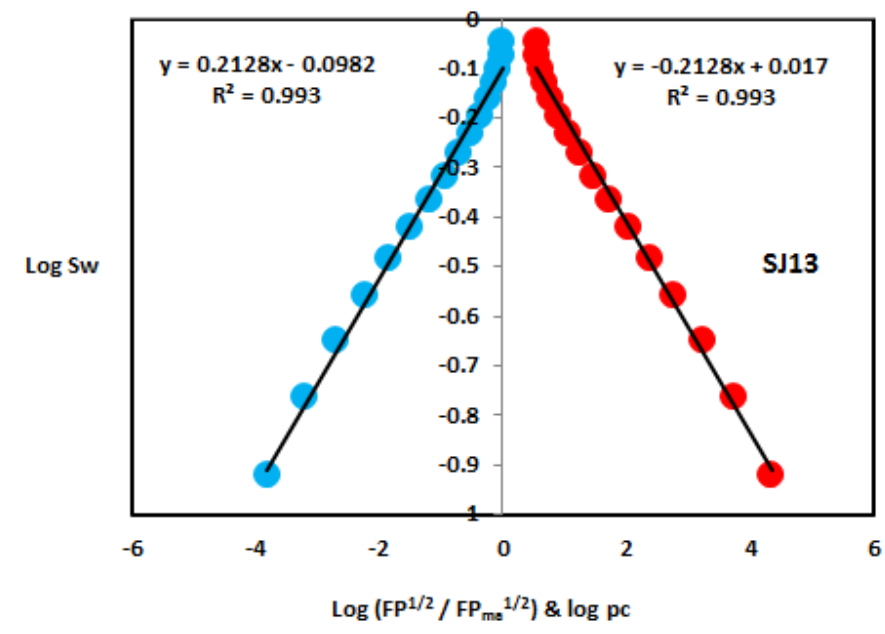

Figure11. $\log \left(F P_{1 / 2} / F P^{1 / 2}{ }_{\text {max }}\right) \& \log$ Pc versus log Sw of sample SJ13.

Overall a plot of positive slope of the first procedure versus negative slope of the second procedure as described in Figure 12 reveals three permeable zones of varying Petrophysical properties. These 
Fluid Potential Fractal Dimension for Characterizing Shajara Reservoirs of the Permo-Carboniferous Shajara Formation, Saudi Arabia

reservoir zone were also confirmed by plotting fluid potential fractal dimension versus capillary pressure fractal dimension as described in Figure 13. Such variation in fractal dimension can account for heterogeneity which is a key parameter in reservoir quality assessment.

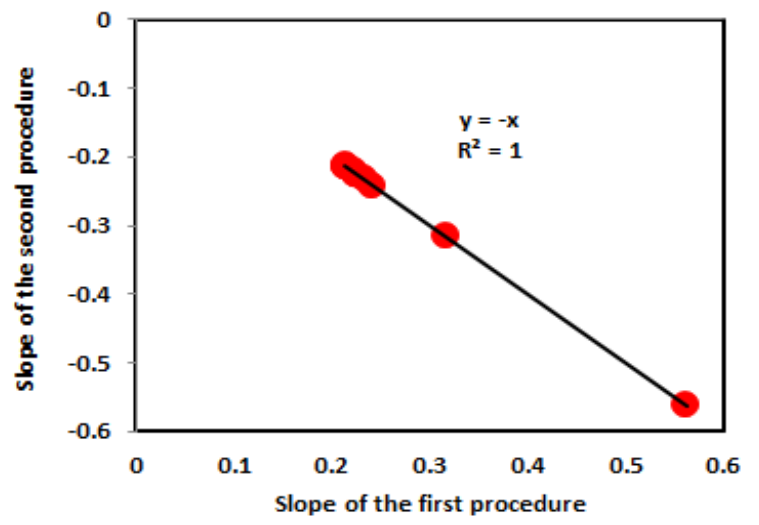

Figure12. Slope of the first procedure versus slope of the second procedure.

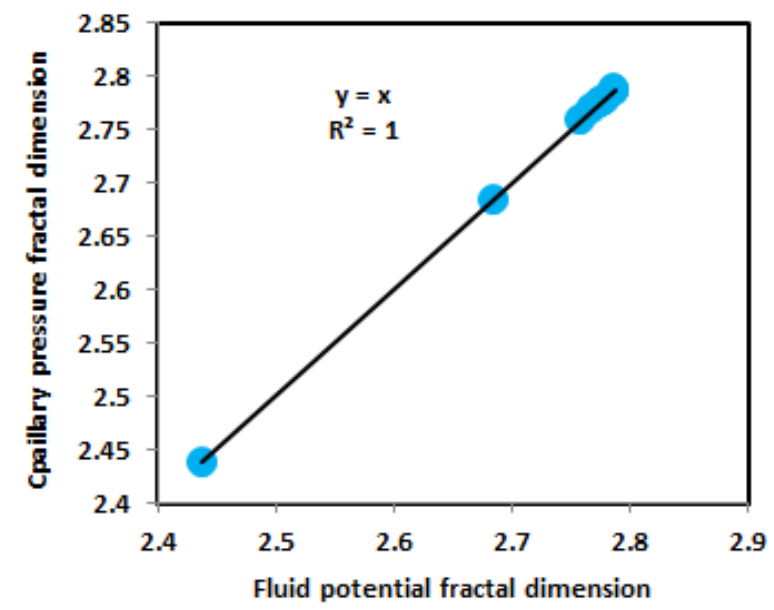

Figure13. Fluid potential fractal dimension versus capillary pressure fractal dimension.

\section{CONCLUSION}

The sandstones of the Shajara Reservoirs of the Shajara formation permo-Carboniferous were divided here into three units based on fluid potential fractal dimension. The Units from base to top are: Lower Shajara Fluid Potential Fractal dimension Unit, Middle Shajara Fluid Potential Fractal Dimension Unit, and Upper Shajara Fluid Potential Fractal Dimension Unit. These units were also proved by capillary pressure fractal dimension. The fractal dimension was found to increase with increasing grain size and permeability owing to possibility of having interconnected channels.

\section{ACKNOWLEDGEMENT}

The author would to thank King Saud University, college of Engineering, Department of Petroleum and Natural Gas Engineering, Department of Chemical Engineering, Research Centre at College of Engineering, and King Abdullah Institute for research and Consulting Studies for their supports.

\section{REFERENCES}

[1] Frenkel, J. On the theory of seismic and seismoelectric phenomena in a moist soil. J physics, 1944, 3:230241. https://olemiss.edu/sciencenet/poronet/frenkel.pdf

[2] Li, K., and Williams, W. Determination of capillary pressure function from resistivity data. Transport in Porous Media, 2007, 67:1-15. https://link.springer.com/article/10.1007/s11242-006-0009-9

[3] Revil, A., and Jardani A. Seismoelectric response of heavy oil reservoirs: theory and numerical modelling. Geophysical Journal International, 2010, 180:781-797. https://academic.oup.com/gii/article/ 180/2/781/ 689125 
[4] Dukhin, A., Goetz, P., and Thommes, M. Seismoelectric effect: a non-isochoric streaming current. 1 experiment,J Colloid Interface Sci,2010, 345:547-553. https://www.Sciencedirect.com/science/ article/pii/ S0021979710001682

[5] Guan, W., Hu, H., andWang, Z. Permeability inversion from low-frequency seismoelectric logs in fluidsaturated porous formations. Geophysical Prospecting, 2012, 61:120-133. https://onlinelibrary.wiley.com/ doi/full/10.1111/j.1365-2478.2012.01053.x

[6] Hu, H., Guan, W., and Zhao, W. Theoretical studies of permeability inversion from seismoelectric logs. Geophysical Research Abstracts, 2012, 14:EGU2012-6725-1 2012 EGU General Assembly 2012. https://meetingorganizer.copernicus.org/EGU2012/EGU2012-6725-1.pdf

[7] Borde C, S'en'echal P, Barri`ere J, Brito D., Normandin E., and Jougnot, D.Impact of water saturation on seismoelectric transfer functions: a laboratory study of co-seismic phenomenon. Geophys J. Int, 2015, 200:1317-1335.

[8] Jardani A., and Revil A. (2015) Seismoelectric couplings in a poroelastic material containing two immiscible fluid phases. Geophysical J International, 2015, 202:850-870.

[9] Holzhauer, J., Brito,D., Bordes,C.,Brun,Y., and Guatarbes, B.Experimental quantification of the seismoelectric transfer function and its dependence on conductivity and saturation in loose sand. Geophys Prospect, 2016, 65: 1097-1120. https://onlinelibrary.wiley.com/doi/abs/10.1111/1365-2478.12448

[10] Ping, R.,Wei,J-X., Di,B-R., Ding, P-o., and Liu, Z-C.Experimental research on seismoelectric effects in sandstone. Applied Geophysics, 2016 13: 425-436. https://link.springer.com/article/10.1007/s11770-0160570-0

[11] Djuraev, U., Jufar,S.R., and Vasant. P. Numerical Study of frequency-dependent seismoelectric coupling in partially-saturated porous media. MATEC Web of Conferences 87, 02001 (2017). https://www. researchgate.net/publication/311630341_Numerical_Study_of_Frequencydependent_Seismoelectric_Coup ling_in_Partially-saturated_Porous_Media

[12] Alkhidir KEME. Pressure head fractal dimension for characterizing Shajara Reservoirs of the Shajara Formation of the Permo-Carboniferous Unayzah Group, Saudi Arabia. Arch Pet Environ Biotech, 2017, 2:1-7. https://www.gavinpublishers.com/articles/Research-Article/Archives-of-Petroleum-EnvironmentalBiotechnology-ISSN-2574-7614/Pressure-Head-Fractal-Dimension-for-Characterizing-ShajaraReservoirs-of-the-Shajara-Formation-of-th

[13] Al-Khidir KE. On Similarity of Pressure Head and Bubble Pressure Fractal Dimensions for Characterizing Permo-Carboniferous Shajara Formation, Saudi Arabia. Journal of Industrial Pollution and Toxicity, 2018, 1:1-10. http://www.annexpublishers.co/articles/JIPT/1102-On-Similarity-of-Pressure-Head-and-BubblePressure-Fractal-Dimensions-for-Characterizing-Permo-Carboniferous-Shajara-FormationSaudi\%20Arabia.pdf

[14] Alkhidir KEME. Geometric relaxation time of induced polarization fractal dimension for characterizing Shajara Reservoirs of the Shajara Formation of the Permo-Carboniferous Unayzah Group, Saudi Arabia. Scifed J Petroleum, 2018, 2:1-6. http://scifedpublishers.com/fulltext/geometric-relaxation-time-of-inducedpolarization-fractal-dimensionfor-characterizing-shajara-reservoirs-of-the-shajara-formation-of-thepermocarboniferous-unayzah-group-saudi-arabia/21960

[15] Alkhidir KEME. Geometric relaxation time of induced polarization fractal dimension for characterizing Shajara Reservoirs of the Shajara formation of the Permo-Carboniferous Unayzah Group-Permo. Int J Pet and Res, 2018, 2:105-108 https://madridge.org/international-journal-of-petrochemistry/ijpr-1000119.pdf

[16] Alkhidir KEME. Arithmetic relaxation time of induced polarization fractal dimension for characterizing Shajara Reservoirs of the Shajara Formation. Nanosci and Nanotechnol. 2(1):1-8. http://ojs.whioce.com/ index.php/nn/article/view/363

[17] AlKhidir KEME 2018. Seismo Electric field fractal dimension for characterizing Shajara Reservoirs of the Permo-Carboniferous Shajara Formation, Saudi Arabia. Pet petro Chem Eng J, 2018, 2:1-8. https:// medwinpublishers.com/PPEJ/PPEJ16000156.pdf

[18] Alkhidir KEME. Resistivity fractal dimension for characterizing Shajara reservoirs of the permocarboniferous Shajara formation Saudi Arabia.Int J Petrochem Sci and Eng, 2018, 3:109-112. https://medcraveonline.com/IPCSE/IPCSE-03-00084.pdf

[19] Alkhidir KEME.(2018) Electro Kinetic Fractal Dimension for Characterizing Shajara Reservoirs of the Shajara Formation. International Journal of Nanotechnology in Medicine and Engineering. 2018,3:1-7. https://biocoreopen.org/ijnme/Electro-Kinetic-Fractal-Dimension-for-Characterizing-Shajara-Reservoirsof-the-Shajara-formation.pdf

[20] Alkhidir KEME. Electric Potential Energy Fractal Dimension for Characterizing Permo-carboniferous Shajara Formation. Expert Opin Environ Biol, 2018, 7:1-5. https://www.scitechnol.com/peer-review/ electric-potential-energy-fractal-dimension-for-characterizing-permocarboniferous-shajara-formationxc7v.php?article_id=7608 
Fluid Potential Fractal Dimension for Characterizing Shajara Reservoirs of the Permo-Carboniferous Shajara Formation, Saudi Arabia

[21] Alkhidir KEME. Electric potential gradient Fractal Dimension for Characterizing Shajara Reservoirs of the Permo-Carboniferous Shajara Formation, Saudi Arabia. Arch Petro Chem Eng, 2018, (1):1-6. https://www. arvinmedonline.org/assets/article-pdf/JPCE-101.pdf

[22] Alkhidir KEME. On Similarity of Differential Capacity and Capillary Pressure Fractal Dimensions for Characterizing Shajara Reservoirs of the Permo-Carboniferous Shajara Formation, Saudi Arabia.Scifed Journal of Biofuel and Bioenergetics,2018, 1: 1-10. https://www.scifedpublishers.com/open-access/onsimilarity-of-differential-capacity-and-capillary-pressure-fractalrndimensions-for-characterizing-shajarareservoirs-of-the-permocarboniferous-shajara-formation-saudi-arabia.pdf

Citation: Khalid Elyas Mohamed Elameen Alkhidir, (2019). "Fluid Potential Fractal Dimension for Characterizing Shajara Reservoirs of the Permo-Carboniferous Shajara Formation, Saudi Arabia”, International Journal of Petroleum and Petrochemical Engineering (IJPPE), 5(1), pp.6-15, DOI: http://dx.doi.org/10.20431/2454-7980.0501002

Copyright: (C) 2019 Authors. This is an open-access article distributed under the terms of the Creative Commons Attribution License, which permits unrestricted use, distribution, and reproduction in any medium, provided the original author and source are credited 